\title{
Writing Progress and Processes of Grade 7 At-Risk French Immersion Students
}

\author{
Josée Le Bouthillier \\ University of New \\ Brunswick, Canada
}

\begin{abstract}
This study presents data collected in a French immersion literacy classroom in New Brunswick, Canada where full inclusion is practiced. The purpose of this ethnographic study was to examine the progress made by four grade 7 at-risk students in their writing processes by comparing think-aloud protocols from November/December to think-aloud protocols from May. This study adopted sociocognitve and cognitive theories as theoretical frameworks. Hayes' [7] writing model was used to analyze the data. Data showed that at-risk students were able to progress in terms of their affective response to writing and in terms of cognitive processes related to translating and revising. Data revealed that explicit teaching, especially modeling, contributed to the progress made by at-risk students. However, at-risk students made little progress in terms of planning, in part because they did not understand its importance. Among the pedagogical implications of this study is the need for explicit teaching related to the importance of planning and setting writing goals. In addition, in revising, surface level elements were the main focus for at-risk students. Teacher-student conferences should focus on deeper level elements.
\end{abstract}

\section{Introduction}

In New Brunswick, Canada's only officially bilingual province, the school system is organized into two linguistic sectors: A French and an English sector. Within the Anglophone sector, two programs are offered: the English program and the French Immersion (FI) program. The Canadian FI program promotes the integration of language learning through content. Also, the New Brunswick Ministry of Education promotes full inclusion for all students regardless of their learning challenges in both its English and FI programs. This poses a particular challenge in the FI program. Due to a lack of research about at-risk students in FI, educational stakeholders such as principals, resource teachers, school psychologists, and English and French teachers tend to discourage at-risk students from entering the FI program [6]. However, despite the lack of research and some contradictory results, most studies indicated that at-risk students' participation in the FI program is not detrimental to their learning [6]. Within the FI program, there is also a lack of support for at-risk students [14], because schools tend to focus on at-risk students in the English program. However, since the publication of the Porter \& AuCoin report on inclusion in 2012 [13], the New Brunswick Department of Education has expressed its willingness to improve the inclusiveness of the FI program.

Writing in FI is also an area of concern, since many studies indicated that writing production represents a particular challenge to students (e.g., [5], [9]). In addition, some studies highlighted the fact that the teaching writing in second language contexts in school is often neglected because teachers feel that they lack the pedagogical expertise necessary to teach it well (e.g., [3], [16]).

This study aims to contribute to research on both at-risk students and writing in FI by comparing atrisk grade 7 FI students writing processes from the beginning and the end of the school year.

\section{Theoretical Framework}

\subsection{Sociocognitive and cognitive theories}

In order to examine at-risk students' writing processes, this study adopted Bandura's [2] sociocognitive theory that posits that human development is explained by the interaction between behavioral, cognitive, personal and environmental factors. Also, this study uses a cognitive theory of writing where writing is perceived as a problem solving activity [1].

\subsection{Writing models}

Because of the complexity related to writing knowledge and the cognitive processes involved, it is difficult to represent them without using a model. 
There are several writing models, each focusing on different aspects of writing. This study adopts primarily the Hayes \& Flower's model [8] and its subsequent revision by Hayes [7].

Hayes and Flower's [8] writing model is the first model that attempted to represent writing processes. Based on think-aloud protocols, this model is comprised of three main parts: task environment, long-term memory and writing processes. Task environment consists of the instructions related to the task such as writing theme, targeted audience and motivating cues. These are external elements of writing for the author, but ones that could influence performance. Long-term memory includes content knowledge, audience knowledge and linguistic knowledge. Finally, the writing processes consist of three major processes: (a) Planning is divided in three sub-processes, generation, organization and goal setting; (b) translating is the process of transforming ideas in actual text, and (c) revision is further divided in two sub-processes, reading and editing. The component "control" ensures the management and control of the different processes by ordering the activation of the three main processes described.

In 1996, Hayes [7] made important changes to the writing model he conceived with his colleague, Linda Flower. He wanted to acknowledge the empirical data collected since the publication of the 1980 model, although he admitted that it is impossible to describe all the important aspects of writing in detail in one model. In his revised model, Hayes acknowledged that writing goes beyond cognitive processes and that it is influenced by the social context within which it is produced and by affective and physical factors. To the task environment component of the previous model, Hayes added two categories: 1) the social environment including the audience and the collaborators; and 2) the physical environment including the text already produced and the composing medium. His model was divided in two parts and the second part is the individual. In this part, he added working memory to the long-term memory. He also added motivation and affect in the individual part of his model, which he further divided in goals, predispositions, beliefs and attitudes, and estimated cost/advantages. He renamed the cognitive processes to text interpretation, reflection and text production. In this study, the original cognitive processes (planning, translating and revising) from Hayes and Flower's model will be kept, since they are the terms most commonly used in the today's literature, but Hayes' revision will be used for its other components.

\subsection{At-risk students and inclusion}

Before discussing the characteristics of at-risk students in writing, it is important to define what is meant by at-risk students and inclusion in this study. According to Genesee [6], (p. 656), at risk is used generically to refer to "all these kinds of students those with language, literacy, and academic difficulties or who are likely to experience such difficulties, whether they stem from what might be considered clinical factors $[\ldots]$ or from non-clinical factors." The New Brunswick Department of Education defines inclusive education as "a pairing of philosophy and pedagogical practices that allow each student to feel respected, confident and safe so he or she can learn and develop to is or her full potential.” ([12], p. 1).

As stated previously, little research has been conducted in regards to at-risk students in FI. In fact, no study deals specifically with the writing of at-risk students in this program. However, several studies have been conducted in the first language context and the English as a second language context (non immersion context). These studies found that at-risk students tend to focus on the product to the detriment of the processes [15]; they devote little time to the planning and the revision of their texts [11]; they consider neither the text's global structure, nor its meaning [10]; and they tend to only focus on level surface features of their text such as spelling, punctuation, capitalization as well as text appearance and letter formation [11]. Therefore, their revisions have little effect on overall text quality. In the research, planning has been identified as a crucial process in order to achieve competency in writing. Gould [17] stated that competent writers devoted 2/3 of their planning time to planning. Hall [18] added that L2 writers needed to devote three times more time to planning than their peers in their L1.

\subsection{Writing teaching practices}

Several writing instructional practices have been deemed effective for all students, including at-risk students [19]. These writing teaching practices include analysis of writing models, shared writing, guided writing, collaborative writing and independent writing. With analysis of writing models, the students, supported by their teachers, analyze and compare writing models in order to extract the text structure and the linguistic elements particular to a specific genre. In shared writing, teachers share their writing processes, strategies and knowledge aloud with the students. Guided writing is similar to modeled writing, but instead of sharing with the whole group of students, teachers think aloud for a small group of students who may be experiencing difficulties with one or more writing concepts taught to the whole group during the 
modeled writing. During collaborative writing, students practice with their peers the writing concepts taught by the teacher before applying these concepts to independent writing. Analysis of writing models, shared writing and guided writing allow the teachers to include explicit teaching in their writing instruction, while collaborative writing and independent writing foster students' consolidation of their writing knowledge [20].

\section{Research Question}

Taking in consideration the need of research both in the areas of writing and at-risks students in FI, the following research question guided this study: How does the knowledge of the writing processes of atrisk students develop during a school year?

\section{Methodology}

To answer the research question, an ethnographic perspective [4] was used. This study is part of a larger study on writing development in French Immersion in which a class of 20 students and 4 teachers were involved. From those 20 students, 8 students were chosen, 4 at-risk students and 4 typically developing students, based on a writing assessment and the perspectives of English and French literacy teachers from grade 7 and from the previous year (grade 6). The present study focuses on the 4 at-risk students.

At two points of time during the school year, in November/December 2012 and in May 2013, students engaged in individual think-alouds with the researcher. Each time, they did two think-alouds in two separate sessions, one during the writing of a story and one while writing a biography. The results section will focus on the think-alouds done while writing a story. Students were also interviewed twice in the school year about their writing knowledge. Interviews were also conducted with the teachers, the resource teacher, the guidance counselor, and the school administration. Students were observed within their literacy class for 47 hours and writing artifacts were collected.

Ed, Luke, Brad and Molly were the 4 at-risk students participating in the study. As per ethics guidelines, the names of these students are pseudonyms. Ed was diagnosed with dysgraphia. Also, he had difficulty organizing his thoughts and providing details when writing. It was difficult for him to understand and to remember a basic conversation, both in English, his first language, and in French. For Ed, staying on subject and getting straight to the point were areas of challenge. He didn't like loud noises and it was also difficult for him to respect the personal space of others. Luke, on the other hand, had no known problems other than performing poorly on writing tasks. Brad suffered from severe asthma and, in grade 6, he missed half of the school year. In addition, he had low cognitive abilities. Molly had Asperger Syndrome on the autism spectrum.

Both in November and in May, students were offered a choice between 10 visual writing prompts related to adventures, careers, sports and general subjects. The participants were informed by the researcher that the study related to how writing knowledge developed during a school year and they were encouraged to write the best text they could for the researcher.

Classroom observations were conducted throughout the 2012-2013 school year and field notes were taken. The French literacy teacher was explicit in her teaching of writing using modeling, analysis of model texts and student-teacher writing conferences. Although she concentrated on deeper level elements in her explicit teaching, student-teacher writing conferences focused on surface level elements such as spelling, grammar and syntax. Time was devoted to the writing processes, especially planning and revising. However, for planning, the teacher would supply graphic organizers to the students and model their use without explaining the different components of the planning process - generation of ideas, organization of ideas and goal setting and without explicitly mentioning how the three components are interrelated [8].

The English literacy teacher used similar teaching practices as the French literacy teacher, although she implemented the student-teacher writing conferences differently. She used the one-on-one time with the specific student to concentrate on their particular needs. For example, Molly had difficulty narrowing her ideas during the planning process. The English literacy teacher devoted her conferencing time with Molly from September to December to this specific problem only. From January to May, Molly and her English literacy teacher concentrated on other elements too, while still working on narrowing ideas.

\section{Results}

The following table summarizes the results.

Table 1. Comparison between November/December think-aloud and May think-aloud

\begin{tabular}{|l|l|}
\hline $\begin{array}{l}\text { November/December } \\
\text { 2012 think-aloud }\end{array}$ & May 2013 think-aloud \\
\hline $\begin{array}{l}\text { Negative attitudes } \\
\text { toward writing, because } \\
\text { writing is a challenge. }\end{array}$ & $\begin{array}{l}\text { Positive attitudes. No } \\
\text { mention of self-doubts or } \\
\text { lack of confidence. }\end{array}$ \\
\hline $\begin{array}{l}\text { In the planning process, } \\
\text { students generated ideas, } \\
\text { but generally did not } \\
\text { develop them. They did }\end{array}$ & \\
\hline
\end{tabular}




\begin{tabular}{|c|c|}
\hline $\begin{array}{l}\text { not set goals and } \\
\text { organize their ideas. }\end{array}$ & \\
\hline $\begin{array}{l}\text { In translating, students' } \\
\text { lack of linguistic } \\
\text { knowledge } \\
\text { difficulties. They did } \\
\text { not interact with their } \\
\text { texts. }\end{array}$ & $\begin{array}{l}\text { The translating process } \\
\text { was smoother because of } \\
\text { a development in the } \\
\text { linguistic knowledge. } \\
\text { They increased their } \\
\text { interactions with their } \\
\text { texts. }\end{array}$ \\
\hline $\begin{array}{l}\text { For revising, students } \\
\text { concentrated on spelling } \\
\text { and grammar. They } \\
\text { made extensive use of } \\
\text { the dictionary even } \\
\text { though they had } \\
\text { difficulty with the task of } \\
\text { looking up words. }\end{array}$ & $\begin{array}{l}\text { Students still focused on } \\
\text { grammar and spelling, } \\
\text { but they gained skills for } \\
\text { using the dictionary. }\end{array}$ \\
\hline
\end{tabular}

With respect to the attitudes and predispositions towards writing, results showed that all students, except Ben, did not like writing in November/December. As the following transcripts show, writing was difficult for them:

\section{Sample transcripts}

\section{Brad}

Je veux, comme j'aime un peu, mais pas vraiment. C'est pas, c'est comme hard pour moi. Je juste, j'aime pas.

[I want, like I like it a little bit, but not really. It is not, it's just hard for me. I just don't like it.]

\section{Molly}

Des fois, c'est pain.

[Sometimes, it's painful.]

Numerous times during their November /December think-aloud, at-risk students expressed self-doubts and a lack of confidence towards their ability to write as the following excerpts show:

\section{Sample transcripts}

\section{Ed}

Mais, c'est en français. Je ne peux pas vraiment écrire très bien, parce que c'est ma langue secondaire.

[But, it's in French. I cannot really write well, because it's my second language.]

Molly

Et j'ai aussi des difficulties avec mes écrire, comme mon spelling et autre chose. [...] Je ne sais pas pourquoi j'ai fait, mais j'ai écrit très mal.

[And I also have difficulties with my writings, like my spelling and other things. [...] I don't know why I did it, but I wrote really bad.]
During the May think-aloud, all four students expressed feeling more positive about writing than they were at the beginning of the year.

\section{Sample transcript}

Luke

C'est juste comme, c'est juste un peu plus facile pour moi. Parce que on a fait beaucoup d'écriture cette année en français, alors c'est comme practice makes perfect.

[It just like, it just easier for me. Because, we wrote a lot this year in French, so it's like practice makes perfect.]

Also, there was no mention of self-doubt or lacking confidence about writing abilities in the May think-aloud transcripts. However, Ed still expressed frustration and anxiety towards the revising process.

In terms of planning, with one noticeable exception, students adopted similar behaviors in November/December and in May. Luke did not plan at all both times. Ed and Luke generated big ideas and chose one, but they didn't add detail to the idea chosen. In November/December, Molly generated 16 big ideas. However, she was never able to commit to one of her ideas. In May, however, Molly generated only one idea and she was able to develop it briefly orally.

When translating in November/December, all students except Luke experienced difficulties. They were frequently blocked by their lack of knowledge in their second language and often expressed that they lacked the abilities to write their text. Brad, for instance, sighed loudly and asked if he could write words in English. Ed stopped in the middle of his text and he was unable to continue without researcher support. Molly laughed nervously and constantly and mentioned her lack of abilities many times. Luke, on the other hand, wrote without being blocked, but he stopped often to shake his hands, expressing that the physical act of writing was painful for him. All of the students interacted rarely with the texts already written and they constantly sought help from the researcher. In May, all students were able to write their text without being blocked. They interacted more with the text already written. They were more likely to stop to think about the quality of their writing output. During these reflection breaks, the students were mainly concerned with conventions such as spelling and word translations from English to French. However, Molly did notice a lack of coherence in the text she had already written and Luke also paid attention to word choice. In fact, Luke did change successfully a word for the better. Ed adopted behaviors that were specific to his learning disability. Concerned with his letter formation because of his dysgraphia, he had 
a tendency to reform his letters, but without rereading the text already written. During the November/December think-aloud, he did not display this preoccupation with his letter formation. All atrisk students except Ed reread the text already written, which none of the students had done at the beginning of the year. Molly and Brad read the text already written three times, while Luke did it twice. They still sought help from the researcher, albeit rarely, displaying more autonomy in controlling their translating process.

In the November/December think-aloud, all students but Molly were able to revise. Ed, Luke and Brad were mostly concerned with spelling and word translation. Ed, for instance, was looking for every word of his text in the dictionary. The three boys devoted most of their revising time to looking in the dictionary. They experienced tremendous difficulty with the dictionary because they were unable to easily find words they were looking for. Ed, because of his dysgraphia, was very concerned about letter formation and he devoted much time to reforming letters. In May, all students, including Molly, were revising, while still concentrating their efforts on spelling and word translation. Ed remained very concerned about his letter formation. However, this time the students were much more efficient with the dictionary, making the revision process much smoother.

\section{Discussion}

The findings of this study confirm the results of other studies regarding the writing processes of atrisk students in French immersion. At the beginning of the year, these students shared the characteristics of their peers in a first language context and in an English as a second language context. These characteristics consist of focusing on the product at the expense of the processes [15], devoting little time to the planning and the revising of their texts [11], considering neither the text's global structure nor its meaning [10] and focusing on surface level features of their texts as well as its appearance and letter formation [11]. The at-risk students maintained these characteristics throughout the school year. However, the results also show that at-risk students in a French immersion program can and do make progress in regards to their use of the writing processes and other aspects of writing such as affective factors.

The most pronounced differences found while comparing the November/December and May thinkalouds related to the affective domain. All students expressed a change in their perceptions towards writing, finding it a more enjoyable activity because their abilities in writing had increased. They didn't indicate self-doubts. These changes could be due to many pedagogical factors. First of all, the French teacher included several general affective activities in the classroom during the school year. More directly linked to writing, the FI teacher supported her students by modeling, analyzing examples, conducting writing conferences, and explicitly teaching knowledge pertaining to the different writing tasks that students engaged in during the school year. Also, students had numerous occasions to write during the school year. The students also had the opportunity to engage in the same type of activities in their first language with their English literacy teacher.

These pedagogical factors may explain the progress made in translating and revising. The modeling and the explicit teaching often focused on the writing processes. During the translation process, students were probably more able to think about the quality of their output because different writing knowledge had been taught during the school year. It allowed the at-risk students to interact with the text that they had already written. Those interactions were still minimal, however, and concentrated mainly on linguistic conventions, that is surface level elements. They were also more able to access the linguistic knowledge needed to transform their ideas into written language. Although at-risk writers still sought the researcher's help during the May think-aloud, especially in regards to English to French word translations, it was less frequent. They had developed a greater autonomy.

During the revising process, in addition to the modeling and the explicit teaching, students were encouraged to do peer revising and to conference with the teacher. All the at-risk students were more at ease with the revising process, even if Ed was still voicing some frustration for this process in particular. However, despite the fact that the teacher emphasized deep level elements during explicit instruction, the at-risk students continued to concentrate their efforts on surface level elements of the text, mainly spelling and word translation. In that sense, the students participating in this study maintained the characteristics of their at-risk counterparts in other studies related to revising. It is interesting to note that, in the classroom, there seemed to have been a dissonance between the teacher discourse related to deep level revising and the practices adopted during student-teacher writing conferences. In these conferences, the French teacher seemed to focus more on writing conventions, maybe because linguistic precision is one of the biggest challenges of French immersion students. The underlying message transmitted to the students during student-teacher conferencing could have been that linguistic conventions were more important than other writing elements such as ideas, organization, word choice and sentence structure. Another possible explanation is that, although at-risk students were becoming more efficient with using 
the dictionary, they still overused it and dedicated too much of their revising time to this strategy. Perhaps teaching at-risk students less time consuming spelling strategies would allow them the time and the cognitive resources to devote to deep surface elements of their text. One of the main difficulties experienced by students while trying to locate a word in the dictionary was determining the spelling of its beginning sound. For example, the sound " $\partial v$ " in French can be represented graphically by "o", "au", "ho", "eau" and so on. Explicitly teaching the different spellings that represent various sounds and posting them on the classroom wall would probably help the students.

Likewise, the at-risk students participating in this study maintained the characteristic of their at-risk counterparts in other studies in that they devoted little time, if any, to planning. The lack of time devoted to planning seemed to affect the implementation of the other writing processes, translating and revising. This is partly due to the fact that when the at-risk students started writing their text, they did not have a clear idea of what their text would consist off. Therefore, since at-risk students didn't consider their text's global structure or its content during the planning process, the other processes were slowed down.

The French teacher provided many planning tools to the students during the school year and modeled the use of these tools. One possible explanation of this lack of progress could be that students were not explicitly informed of why planning is important. In addition, the planning process is comprised of three components, namely generating ideas, organizing ideas and goal setting. Neither the French literacy teacher nor the English teacher explicitly taught how these three components are linked and how to use them in relation to other during the planning process. Also, goal setting was never mentioned during the school year. Explicit teaching related to setting writing goals would help students consider the text's global structure and their writing purpose. Considering the importance of the planning process [17] for developing writing skills, and the importance of this process for L2 writers [18], it seems imperative for the literacy teachers to devote some teaching time to this process. This instructional time could contribute to students' understanding of its role for successful writing as well as the different sub-processes and how these sub-processes interact together.

In terms of planning, however, Molly was able to make some progress. She credited her gains to the explicit teaching on the narrowing of ideas done by her English literacy teacher during conferencing. This suggests that using the teacher-student conference time to target the specific needs of the atrisk learner is beneficial. At-risk students might progress further in their writing processes if these conferences were also used in their French immersion literacy class to individualize instruction instead of devoting time mostly to correcting surface level elements such as spelling and grammar.

Another way to individualize instruction, which seems to be important and necessary for at-risk students in a French immersion context, would be to implement the guided writing instructional practice. Neither the French nor the English literacy teacher used that practice. Writing instructional practices targeting the whole class appeared to be beneficial for at-risk students, but not sufficient to encourage students to adopt more complex planning and revising practices. Depending on their learning difficulty or syndrome, at-risk students have specific needs that cannot be met through instruction directed to the whole group of students alone. For example, at the middle school level, grade 6 to 8 (age 11 to 15 years old), teachers are very unlikely to devote any instructional time to spelling strategies or letter formation. However, it is clear from the results of this study that some at-risk students do need interventions on these two aspects as it affects their writing processes.

\section{Conclusion}

This study aimed to provide more insights about at-risk writers in French immersion to contribute to filling the gap in research in this area. The findings support the idea that at-risk students can successfully be included in an immersion setting and make some progress in their writing competency.

Despite some commonalities between the 4 at-risk students, it is important to specify that there were differences between them. Within a group of at-risk writers, each individual has specific needs depending on his or her learning difficulty or syndrome. For example, Molly, due to her Asperger syndrome, had particular challenges regarding planning. It is difficult for students with Asperger to choose a writing idea. Therefore, because her English literacy teacher responded to her specific needs through individualized instruction during writing conferences, contrary to her at-risk peers in this study, Molly was able progress in planning from the beginning of the year to the end of the year. This has implications for teaching. Teachers should use teaching strategies targeting at-risk students and students in general, such as modeled writing, shared writing and collaborative writing, because they are beneficial to the students. However, teacher-student writing conferences as well as guided writing should be used to individualize instruction and to target specific challenges. During conferencing, it would be important for teachers to move away from focusing on the correction of surface level features and include other elements such as ideas, organization, word choice and sentence structure. 
The teacher should engage the at-risk students in problem-solving, pointing out elements and providing clues without necessarily giving the solution. It could allow the students to interact more with the text already written in broadening their perspective beyond surface level elements.

On the other hand, during guided writing, teachers should include a focus on elements such as spelling and letter formation and provide time for practice in order for at-risk students to achieve a certain level of competency in these areas. This instructional focus should come before teacher-student conferencing where students are at the revising stage. At-risk students' concerns about spelling and letter formation took the majority of their writing time during independent writing. Therefore, if these surface level elements could be addressed prior to independent writing so at-risk students could achieve a certain level of comfort with them, it would allow the students more time to consider deeper level elements.

At-risk students in this study benefited from modeling and explicit instruction. However, another implication of this study is that teachers should model the entire planning process as well as the use of specific tools. It would also be important to discuss with students the purpose of planning and of goal setting.

Finally, the use of dictionary presented a major difficulty during the revising process for at-risk students. A pedagogical implication stemming from this finding is that teachers should provide specifically designed linguistic tools, such as word walls or a class dictionary.

\section{Future Directions}

Future directions for this research include focusing on a specific learning difficulty or syndrome. Also, collecting think-aloud data from more at-risk French Immersion students would provide additional insight into this particular topic.

\section{References}

[1] Alamargot, D. \& Chanquoy, L. (2001). Through the Models of Writing. Dordrechet, Netherlands: Kluwer Academic Publishers.

[2] Bandura, A. (2002). Social Cognitive Theory in Cultural Context. Applied Psychology: An International Review, 51(2), 269-290.

[3] Bournot-Trites, M. (2008). Vison pour le soutien des acquis linguistiques des enseignants de FLS. Revue canadienne de linguistique appliquée, 11(1), 21-40.

[4] Cambra Giné, M. (2003). Une approche ethnographique de la salle de classe de langue. Paris: Didier.
[5] Cormier, M. \& Turnbull, M. (2009). Une approche littératiée: apprendre les sciences et la langue en immersion. La Revue canadienne des langues vivantes, 65(5), 817-840.

[6] Genesee, F. (2007). French Immersion and At-Risk Students: A Review of Research Evidence. The Canadian Modern Language Review, 63(5), 655-688.

[7] Hayes, J. R. (1996). A New Framework for Understanding Cognition and Affect in Writing. In C.M. Levy \& S. Randsdell (Eds.). The Science of Writing: Theories, Methods, Individual Differences and Applications. (p. 1-27). Mahwah, NJ : Lawrence Erlbaum Associates.

[8] Hayes, J. R. et Flower, L. (1980). Identifying the Organisation of Writing Processes. In L. Gregg \& E. Steinberg (Eds.). Cognitive Processes in Writing. (p. 330). Hillsdale, NY: Lawrence Erlbaum Associate.

[9] Lapkin, S., Swain, M. \& Smith, M. (2002). Formulation and the Learning of French Pronominal Verbs in a Canadian French Immersion Context. The Modern Language Journal, 86(4), 45-507.

[10] Leki, I, Cumming, A. \& Silva, T. (2008). A Synthesis of Research on Second Language Writing in English. New York: Routledge.

[11] Lin, S.-J., Monroe, B. \& Troia, G. (2007). Development of Writing Knowledge in Grades 2-8: A Comparison of Typically Developing Writers and Their Struggling Peers. Reading \& Writing Quarterly, 23, 207230 .

[12] New Brunswick Government. (2009). Inclusive Education. Fredericton: New Brunswick. Retrieved from www.gnb.ca/0000/publications/Definition $\% 20$ of $\% 20$ inclus ion.pdf. Access Date: January $15^{\text {th }}, 2015$.

[13] Porter, G. \& Aucoin, A. (2012). Strenghtening Inclusion, strengthening schools. Report of the Review of Inclusive Education Programs and Practices in New Brunswick Schools. An Action Plan for Growth. Fredericton: Province of New Brunswick. Retrieved from www.gnb.ca/0000/publications/comm/InclusionActionPlan Report.pdf. Access Date: January $15^{\text {th }}, 2015$.

[14] Rehorick, S., Dicks, J., Kristmanson, P. \& Cogswell, F. (2006). Quality Learning in French Second Language in New Brunswick: A Brief to the Department of Education. $\quad$ Retrieved from www.unbf.ca/L2/Research/current/documents/FSLStudyU NBreportcomplete.pdf. Access Date: March 16, 2014.

[15] Saddler, B. \& Graham, S. (2007). The Relationship Between Writing Knowledge and Writing Performance Among More and Less Skilled Writers. Reading and Writing Quarterly, 23(3), 231-247.

[16] Vigner, G. (2012). Écrire en FLE. Quel enseignement pour quel apprentissage. Le français dans le monde, 51, 16-33. 
[17] Gould, J. (1980). Experiments on composing letters: Some facts, some myths, and some observations. In L.W. Gregg \& E.R. Steinberg (Eds.). Cognitive processes in writing. (pp. 97-127). Hillsdale, NJ: Lawrence Erlbaum Associates.

[18] Hall, K. (1995). Processus d'écriture en immersion. The Canadian Modern Language Review/ La Revue canadienne des langues vivantes, special issue, 78-100.

[19] Trehearne, M. (2006). Littératie de la 3e à la 6e année. Toronto : Thomson Nelson.

[20] Le Bouthillier, J. \& Dicks, J. (2013). L'emploi d'un modèle d'enseignement systématique d'écriture : Une étude de cas en 7e année de l'immersion précoce.

Revue canadienne des langues vivantes, 69(3). 